\title{
Some Properties of Group-III Nitride Thin Films Directly Grown on Non-Single-Crystalline Substrates by Using a Molecular Beam Epitaxy Apparatus
}

\author{
Yuichi Sato, Shota Ishizaki, Yoshifumi Murakami, Mohamad Idham, Nur Ain, \\ Tatsuya Matsunaga \\ Department of Electrical and Electronic Engineering, Graduate School of Engineering and Resource Science, \\ Akita University, Akita, Japan \\ Email: yusato@gipc.akita-u.ac.jp
}

Received 15 July 2015; accepted 18 August 2015; published 21 August 2015

Copyright (C) 2015 by authors and Scientific Research Publishing Inc.

This work is licensed under the Creative Commons Attribution International License (CC BY). http://creativecommons.org/licenses/by/4.0/

(c) (i) Open Access

\section{Abstract}

Gallium nitride (GaN) and indium-gallium nitride $\left(\operatorname{In}_{\mathrm{x}} \mathrm{Ga}_{1-\mathrm{x}} \mathrm{N}\right)$ thin films were directly grown on several non-single-crystalline substrates such as quartz glass and amorphous-carbon-coated graphite. The films were grown by using a molecular beam epitaxy apparatus having single or dual nitrogen radio-frequency plasma cells, and in addition, germanium (Ge) or magnesium (Mg) doping to the films was also attempted. Crystallinity, photoluminescence (PL) property, and electrical property of the obtained films were investigated. Highly c-axis oriented GaN and $\operatorname{In}_{\mathrm{x}} \mathrm{Ga}_{1-\mathrm{x}} \mathrm{N}$ thin films were obtained on the non-single-crystalline substrates. Near-band-edge emissions were observed in their PL spectra and the intensities were strongly enhanced by Ge doping. Ge doping was also effective on reducing resistivity of the GaN thin films grown on the non-single-crystalline substrates. Electrochemical capacitance-voltage measurements were carried out on the Mg-doped GaN thin films; and p-type conduction in the films was confirmed.

\section{Keywords}

GaN, InGaN, Amorphous Carbon, Graphite, Quartz Glass, Ge Doping, Mg Doping

\section{Introduction}

Nitride compound semiconductors, such as gallium nitride $(\mathrm{GaN})$ and indium-gallium nitride $\left(\operatorname{In}_{\mathrm{x}} \mathrm{Ga}_{1-\mathrm{x}} \mathrm{N}\right)$ alloys 
have been applied for highly efficient light-emitting diodes (LEDs) and laser diodes (LDs) [1]-[4]. Direct energy-band-gaps of $\operatorname{In}_{\mathrm{x}} \mathrm{Ga}_{1-\mathrm{x}} \mathrm{N}$ alloys range between about 0.7 and $3.4 \mathrm{eV}$ [5]-[8] depending upon their molar fractions. Therefore, the nitride semiconductors have been also expected as optoelectronic-conversion materials for highly efficient solar cells in addition to such light-emitting devices. That is, the nitride semiconductors have considerable potentials for their applications to various optoelectronic devices.

Most of the group-III nitride semiconductor thin films are grown on single-crystalline substrates such as sapphire wafers to obtain superior crystallinities which connect to superior electrical and optical properties of the films. Recently, productions of sapphire wafers, which have been the most popular single crystalline substrate used for the growths of nitride semiconductors, have been rapidly developed. Their production costs have been drastically decreased and also the wafer sizes have been expanded. In addition, growths of nitride semiconductor thin films have been developed also on silicon single-crystalline substrates. These single-crystalline wafers still have sufficient availability for the heteroepitaxial growths of the nitride semiconductor thin films.

Nevertheless, the range of application of the nitride semiconductor thin films will become much wider if the films having a certain level of qualities will be obtainable on non-single-crystalline substrates. In general, single-crystalline thin films cannot be obtained on non-single-crystalline substrates. Crystallinities of such films are markedly inferior compared to those of films epitaxially grown on single-crystalline substrates. Growths of the nitride semiconductor thin films on non-single-crystalline substrates have been investigated by several research groups until now. InN, GaN, and InGaN thin films were prepared on glass substrates by the reactive sputtering methods [9]-[11], the reactive evaporation methods [12] [13], the chemical vapor deposition methods [14]-[18], and the molecular beam epitaxy methods [19] [20]. In addition, growths of the nitride semiconductor thin films on polycrystalline substrates such as metal substrates and/or metal thin film deposited glass substrates have been also reported [21]-[24]. The polycrystalline structures of the films grown on the polycrystalline substrates were successfully improved to highly c-axis oriented structures by inserting an amorphous intermediate layer which has enough thickness to isolate the effect of the polycrystalline substrate [22] [25].

GaN-based light-emitting diodes (LEDs) fabricated on non-single-crystalline substrates have been rarely reported until now. One of them is an LED grown by a metal-organic vapor-phase-epitaxy (MOVPE) method on quartz glass substrate; however, the emission intensity from the LED was not always sufficient [26]. Another report is about relatively high-efficient GaN-based LEDs using a fused-silica glass substrate [27]. The GaN thin film was grown on a titanium film deposited on the glass substrate. The fabrication process is consisted of a lot of procedures, and therefore, low cost in the device fabrication, which is one of the merits of the non-crystalline substrates, seems to be disappeared by the complicated processes. More simple fabrication processes will be required in near future to utilize the advantages of the non-single-crystalline substrates.

In addition to the above, properties of impurity-doped nitride semiconductor thin films grown on non-singlecrystalline substrates have not always been sufficiently reported. Moreover, InGaN film growths on non-singlecrystalline substrates and their properties have not been also sufficiently reported. Therefore in this work, some nitride semiconductor thin films were directly grown on several non-single-crystalline substrates by using an MBE apparatus. Some properties, such as crystallinities, electrical and optical properties of the obtained films were investigated. Germanium $(\mathrm{Ge})$ and magnesium $(\mathrm{Mg})$ doping to the films were also attempted and their properties were investigated.

\section{Experimental Methods}

The non-single-crystalline substrate materials used in this work are a synthetic quartz glass, an amorphous-carbon, and an amorphous-carbon-coated graphite. Each of the thicknesses of the substrates is about $0.4 \mathrm{~mm}$. GaN and $\mathrm{In}_{\mathrm{x}} \mathrm{Ga}_{1-\mathrm{x}} \mathrm{N}$ thin films were directly grown on the substrates by an MBE apparatus without any buffer layers. Base pressure of the MBE apparatus reaches to the order of $10^{-8} \mathrm{~Pa}$ by a turbo-molecular-pump evacuation. Single radio-frequency (RF; $13.56 \mathrm{MHz}) \mathrm{N}_{2}$ plasma cell for supplying active nitrogen was used mainly for the GaN thin film growths, and dual RF $N_{2}$ plasma cells were used mainly for the $\operatorname{In}_{x} G_{1-x} N$ thin film growths. The RF powers of $400 \mathrm{~W}$ were supplied to the each plasma cell in which purified $\mathrm{N}_{2}$ flowed at $3 \mathrm{sccm}$, respectively. Ge was adopted for an n-type dopant because of much easiness in its supplying compared with silicon ( $\mathrm{Si}$ ) doping in the growth. On the other hand, $\mathrm{Mg}$ was adopted for p-type doping. The metals of $\mathrm{Ga}$, In, Ge, and $\mathrm{Mg}$ were respectively supplied from Knudsen-cells (K-cells) in which pyrolytic boron nitride crucibles were set. Thickness of the each thin film was around $300 \mathrm{~nm}$. 
Crystallinity of the obtained films was evaluated by X-ray diffraction (XRD) measurements. Compositions of obtained $\operatorname{In}_{\mathrm{x}} \mathrm{Ga}_{1-\mathrm{x}} \mathrm{N}$ thin films were determined by adopting the Vegard's law to the lattice constants obtained from the XRD measurements. Photoluminescence (PL) properties of them were evaluated by using a He-Cd laser $(325 \mathrm{~nm})$ irradiation and detecting the luminescence by a multichannel spectroscope having a Si CCD detector. The measurement samples were cooled down to about $13 \mathrm{~K}$ by set them in a closed-cycle helium cryostat. Electrical properties of them were evaluated by the van der Pauw method. Electrochemical capacitance-voltage (ECV) measurements were carried out to confirm the conduction types in the obtained films. In this case, a heavily Ge-doped GaN conducting underlayer was inserted between the GaN thin film and the insulating quartz glass substrate to enable the ECV measurement.

\section{Results and Discussion}

\subsection{Crystallinities and PL Properties of the Films Directly Grown on the Quartz Glass and Amorphous-Carbon-Coated Graphite Substrates}

Firstly, GaN thin films were grown on several substrates, that is, a synthetic quartz glass, an amorphous-carboncoated graphite, and a c-face sapphire single-crystalline wafer as a reference. The films were directly grown on the each substrates at the growth temperature of $900^{\circ} \mathrm{C}$, and their crystallinities and PL properties were compared. XRD patterns of the films are shown in Figure 1, respectively. In the case of the GaN thin film grown on the quartz glass substrate, only (0002) and (0004) GaN diffraction peaks relating the wurtzite-type crystal structure are observed in the XRD pattern, and it is similarly to the case of the film grown on the c-face sapphire substrate as shown in Figure 1(a) and Figure 1(b), respectively. Therefore, the thin film grown on the quartz glass substrate is at least highly c-axis preferential orientated $\mathrm{GaN}$, though there was a clear difference in their crystallinities. That is, full-widths at the half-maximum (FWHMs) of the X-ray rocking curves (XRCs) of the (0002) $\mathrm{GaN}$ diffractions of the films were largely different as the cases on the quartz glass was $7.6^{\circ}$ and on the sapphire was $0.7^{\circ}$.

The XRD pattern of the GaN thin film grown on the amorphous-carbon-coated graphite substrate is shown in Figure 1(c). The base material of the substrate is a polycrystalline graphite, and an amorphous-carbon layer of several $\mu \mathrm{m}$ thickness is coated on the graphite base. In the XRD pattern, the diffraction peaks of the substrate are indicated by asterisks. Relatively narrow and broad peaks are simultaneously observed, and they respectively correspond to the peaks of the polycrystalline graphite and amorphous-carbon layer. From the consideration,
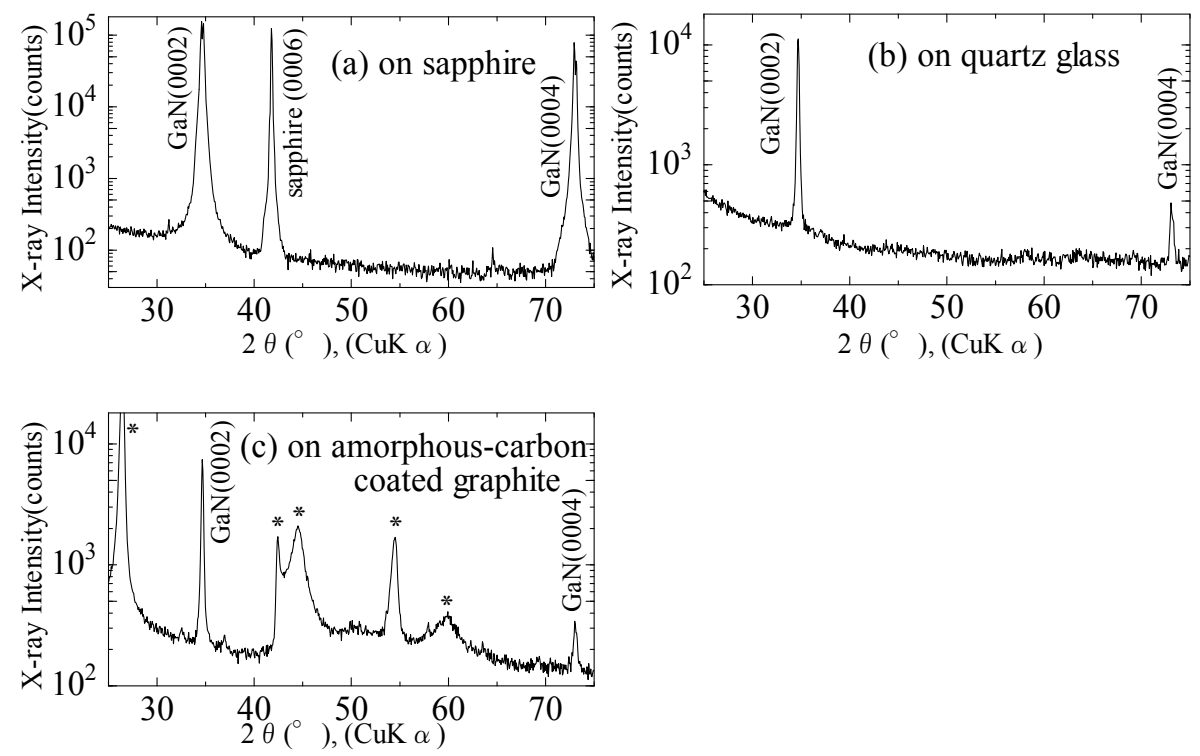

Figure 1. XRD patterns of the GaN thin films grown directly on the (a) c-face single-crystalline sapphire, (b) quartz glass, and (c) amorphous-carbon-coated graphite substrates. The growth temperature of the films was $900^{\circ} \mathrm{C}$. Asterisks in figure (c) mean XRD peaks of the amorphouscarbon-coated graphite substrate. 
it can be said that the film grown on the amorphous-carbon-coated graphite substrate is also highly c-axis oriented GaN since the only (0002) and (0004) GaN diffraction peaks are observed except the peaks caused from the substrate material in the XRD pattern.

Nitride semiconductor thin films often become poor polycrystalline when they are grown on polycrystalline substrates because of random crystal orientations in the polycrystalline substrates [21]. On the other hand, the poor polycrystalline state is well improved and highly c-axis oriented nitride thin films are obtained when an amorphous layer having around $1 \mu \mathrm{m}$ thickness is inserted between the nitride thin films and such polycrystalline substrates [22] [25]. Therefore, the similar effect on the crystallinity is considered to be occurred in the case of the GaN thin film grown on the amorphous-carbon-coated graphite substrate.

Figure 2 shows PL spectra of the GaN thin films grown on the same substrates described above. Band-edge emission at the higher photon energy and deep-level emission at the lower photon energy are respectively observed in the PL spectrum of the GaN thin film grown on the quartz glass substrate as shown in Figure 2(b). This is similar to the case of the film grown on the sapphire substrate shown in Figure 2(a) though the emission intensity of the band-edge emission at the higher energy side is weaker than that of the film grown on the sapphire substrate. On the other hand, broad emission peak at around $3 \mathrm{eV}$ is observed in addition to the band-edge emission at the higher energy side in the PL spectrum of the GaN thin film grown on the amorphous-carboncoated graphite substrate. It is different from the other PL spectra of the GaN films grown on the quartz glass or sapphire substrates.

Next, impurity doping was attempted to GaN thin films grown on the non-single-crystalline substrates and their PL properties were investigated. Doping of impurities such as $\mathrm{Si}, \mathrm{Ge}$, and $\mathrm{Mg}$ to the epitaxial nitride semiconductor thin films is known as an effective way to enhance the luminescence intensities [28] [29]. Ge is an n-type dopant for the nitride semiconductors [29], and its vapor pressure is higher than $\mathrm{Si}$ which is the most popular n-type dopant [28] for the nitride semiconductors. Therefore, the doping of Ge in the MBE apparatus, in which materials are thermally evaporated and supplied to synthesis nitride semiconductor thin films, is much easier than $\mathrm{Si}$, and heavy doping of $\mathrm{Ge}$ to nitride thin films becomes possible [30]. From the reasons, doping of Ge was carried out on the GaN thin films grown on the non-single-crystalline substrates.

Figure 3 shows the PL spectra of the Ge-doped GaN thin films grown on the same substrates. The growth temperature of the each films was $900^{\circ} \mathrm{C}$, and Ge was supplied at the cell temperature of $1200^{\circ} \mathrm{C}$. Similarly


Figure 2. PL spectra of the GaN thin films grown directly on the (a) c-face single-crystalline sapphire, (b) quartz glass, and (c) amorphous-carbon-coated graphite substrates. The growth temperature of the films was $900^{\circ} \mathrm{C}$.
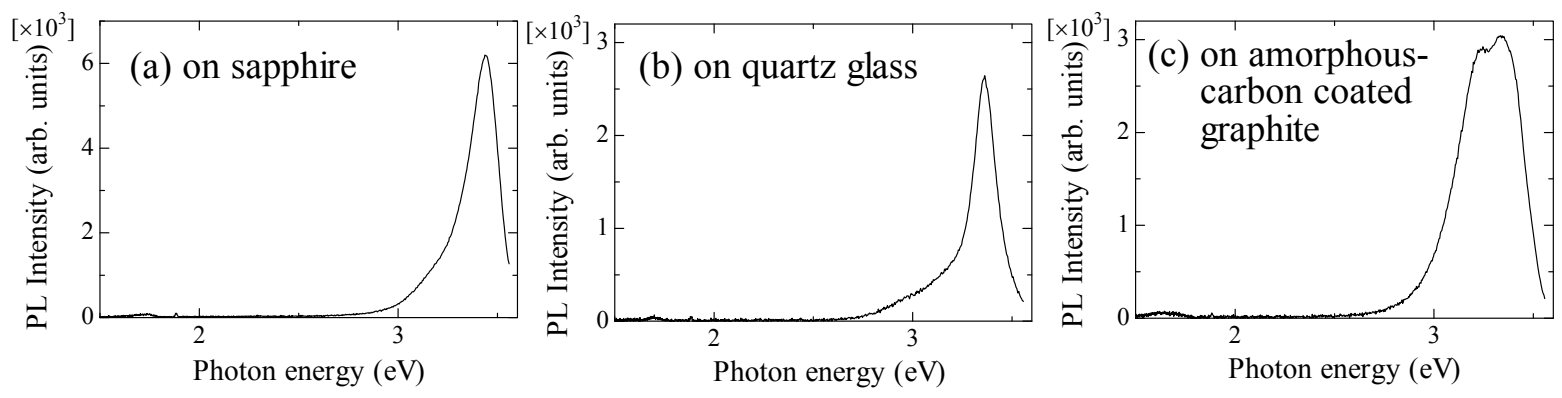

Figure 3. PL spectra of the Ge-doped GaN thin films grown directly on the (a) c-face single-crystalline sapphire, (b) quartz glass, and (c) amorphous-carbon coated graphite substrates. The growth temperature of the films was $900^{\circ} \mathrm{C}$. 
to the case in which the film was grown on the sapphire substrate as shown in Figure 3(a), the emission peaks which correspond to the near band-edge emission were drastically increased compared with those of the undoped GaN thin films as shown in Figure 2. The increases of the near band-edge emission intensities by the Ge doping are considered that the impurity levels have become effective luminescence centers replacing band-toband transitions. In the case of the Ge-doped GaN thin film grown on the amorphous-carbon-coated graphite substrate, the near band-edge emission intensity also increased though the emission peak at the slightly lower energy side remained.

Highly c-axis oriented GaN thin films were obtained on the non-single-crystalline substrates and near bandedge emission intensities in their PL spectra were enhanced by Ge doping. Next, $\operatorname{In}_{x} G a_{1-x} N$ thin films of several compositions were grown on the substrates and their properties were investigated. Firstly, the $\operatorname{In}_{\mathrm{x}} \mathrm{Ga}_{1-\mathrm{x}} \mathrm{N}$ thin films were grown on the quartz glass substrate. The growth temperature and the $\mathrm{Ga}$ cell temperature were fixed to $800^{\circ} \mathrm{C}$ and $970^{\circ} \mathrm{C}$, respectively. On the other hand, the In cell temperature was varied from $760^{\circ} \mathrm{C}$ to $780^{\circ} \mathrm{C}$, and as a result, $\mathrm{In}_{0.1} \mathrm{Ga}_{0.9} \mathrm{~N}$ and $\mathrm{In}_{0.16} \mathrm{Ga}_{0.84} \mathrm{~N}$ thin films were respectively obtained. The XRD patterns of the $\mathrm{In}_{\mathrm{x}} \mathrm{Ga}_{1-\mathrm{x}} \mathrm{N}$ thin films are shown in Figure 4. Phase separation, which is often appeared in $\operatorname{~n}_{x} \mathrm{Ga}_{1-\mathrm{x}} \mathrm{N}$ thin film, was not observed in the obtained thin films and each of them exhibited highly c-axis oriented crystal structures.

PL properties of the $\operatorname{In}_{x} \mathrm{Ga}_{1-\mathrm{x}} \mathrm{N}$ thin films are shown in Figure 5. The value of the energy band gap of $\operatorname{In}_{\mathrm{x}} \mathrm{Ga}_{1-\mathrm{x}} \mathrm{N}$ varies as a function of the molar fraction $\mathrm{x}$ with a certain bowing. The values of the energy band gaps of the obtained $\mathrm{In}_{\mathrm{x}} \mathrm{Ga}_{1-\mathrm{x}} \mathrm{N}$ thin films were respectively estimated as about 3.0 and $2.8 \mathrm{eV}$ under a consideration of the bowing parameter. Near band-edge emissions at the higher energy sides were observed in the PL spectra, though other emission peaks, which were considered to correspond to deep-level emissions, were also observed at the lower energy sides. Similar tendencies were observed in the properties of the ${\operatorname{~} n_{x}} \mathrm{Ga}_{1-\mathrm{x}} \mathrm{N}$ thin film directly grown on the amorphous-carbon-coated graphite substrate. The XRD pattern and PL spectrum of the $\operatorname{In}_{0.1} \mathrm{Ga}_{0.9} \mathrm{~N}$ thin film grown on the amorphous-carbon-coated graphite substrate are shown in Figure 6, respectively. Only the diffraction peaks relating to the c-face of $\operatorname{In}_{\mathrm{x}} \mathrm{Ga}_{1-\mathrm{x}} \mathrm{N}$ were observed in the XRD pattern except the diffraction peaks relating to the substrate used. That is, highly c-axis oriented thin film was obtained, and in addition, phase separation was not observed in this case. Near band-edge emission peak and an emission peak which was
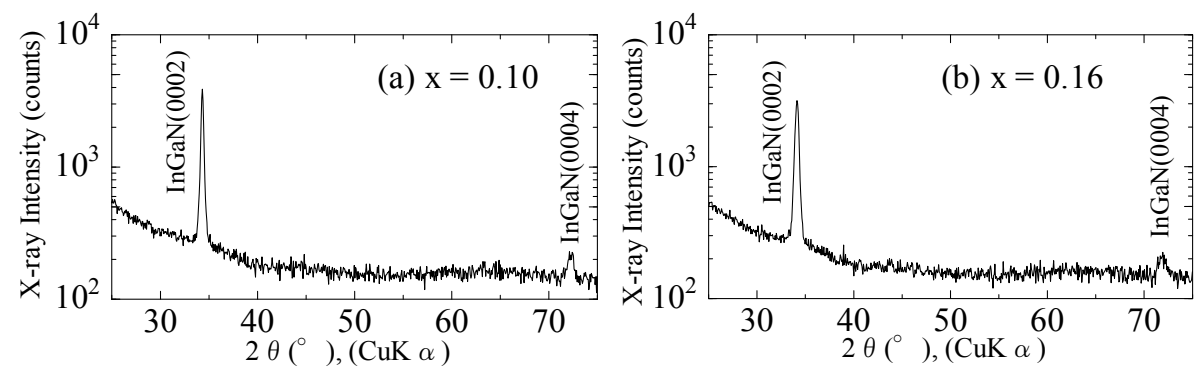

Figure 4. XRD patterns of the $\operatorname{In}_{\mathrm{x}} \mathrm{Ga}_{1-\mathrm{x}} \mathrm{N}$ thin films grown directly on the quartz glass substrates. The growth temperature of the films was fixed to $800^{\circ} \mathrm{C}$. The molar fraction $\mathrm{x}$ of the obtained thin films were (a) 0.10 and (b) 0.16 , respectively.
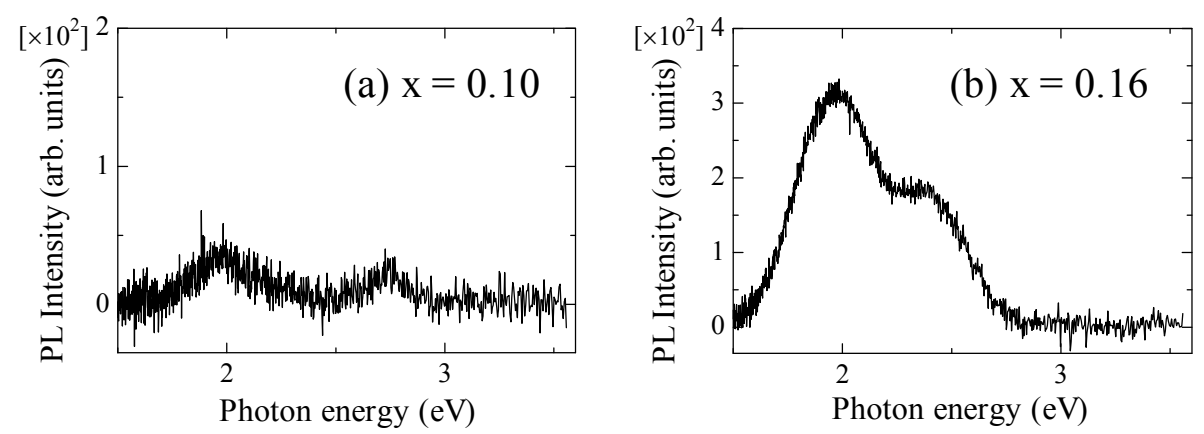

Figure 5. PL spectra of the $\operatorname{In}_{\mathrm{x}} \mathrm{Ga}_{1-\mathrm{x}} \mathrm{N}$ thin films grown directly on the quartz glass substrate. The growth temperature of the films was fixed to $800^{\circ} \mathrm{C}$. The molar fractions $\mathrm{x}$ of the obtained thin films were (a) 0.10 and (b) 0.16 , respectively. 
considered to be caused from deep-level defects were observed in the PL spectrum. The PL peak intensity in the higher energy side is relatively higher than that of the $\mathrm{In}_{0.1} \mathrm{Ga}_{0.9} \mathrm{~N}$ thin film grown on the quartz glass substrate. There might be a different mechanism connecting to the enhancement of the near band-edge emission in this case.

Ge doping was also attempted to the $\operatorname{In}_{\mathrm{x}} \mathrm{Ga}_{1-\mathrm{x}} \mathrm{N}$ thin film grown on the quartz glass substrate. It had been confirmed that the Ge doping to the $\mathrm{GaN}$ thin films directly grown on the non-single-crystalline substrates brought increases of the near band-edge emission intensities in their PL spectra as described before. A similar result was obtained in the case of Ge-doping to the $\operatorname{In}_{x} \mathrm{Ga}_{1-\mathrm{x}} \mathrm{N}$ thin film as shown in Figure 7. The Ge cell temperature was $1100^{\circ} \mathrm{C}$ in this case. Effective luminescence centers might be occur in the $\operatorname{In}_{x} \mathrm{Ga}_{1-x} \mathrm{~N}$ thin film by the doping similarly to the cases of the GaN thin films grown on the same substrate.

\subsection{Some Electrical Properties of the Ge and Mg-Doped GaN Thin Films Grown on the Non-Single-Crystalline Substrates}

Highly c-axis oriented films were obtained and increases of the near band-edge emission intensities by Ge doping were confirmed about the thin films directly grown on the non-single-crystalline substrates as described above section. Some effects of $\mathrm{Ge}$ or $\mathrm{Mg}$-doping to $\mathrm{GaN}$ thin films grown on non-single-crystalline substrates are described in this section. Firstly, effects of n-type Ge-doping were investigated on the resistivity of the GaN thin films. The Ge-doped GaN thin films were directly grown on the quartz glass substrate. The growth temperature was fixed to $900^{\circ} \mathrm{C}$, and the $\mathrm{Ge}$ cell temperature was varied from $1200^{\circ} \mathrm{C}$ to $1300^{\circ} \mathrm{C}$. The variation of the resistivity is shown in Figure 8. The resistivity gradually decreased with the increase of the Ge cell temperature, that is, free electron density increased by the increase of the amount of the n-type impurity. The carrier density in the thin film was confirmed by a Hall effect measurement, and it reached to $3 \times 10^{20} \mathrm{~cm}^{-3}$ when Ge was doped to it at the cell temperature of $1300^{\circ} \mathrm{C}$. Thus, Ge doping is quite effective to obtain GaN thin films of high carrier density when the film is grown on the non-single-crystalline substrate similarly to the epitaxial nitride thin films.

Next, effects of Mg doping were investigated on controlling conduction types of $\mathrm{GaN}$ thin films grown on the


Figure 6. (a) XRD pattern and (b) PL spectrum of the $\operatorname{In}_{0.1} \mathrm{Ga}_{0.9} \mathrm{~N}$ thin film grown directly on the amorphous-carbon-coated graphite substrate. The growth temperature of the film was $800^{\circ} \mathrm{C}$. Asterisks in figure (a) mean XRD peaks of the amorphous-carbon-coated graphite substrate.



Figure 7. PL spectrum of the Ge-doped $\mathrm{In}_{0.1} \mathrm{Ga}_{0.9} \mathrm{~N}$ thin film grown directly on the quartz glass substrate. The growth temperature of the film was $800^{\circ} \mathrm{C}$. 
non-single-crystalline substrates. Effects of Mg-doping to GaN thin films grown on such non-single-crystalline substrates have not been well described, though $\mathrm{Mg}$ is the well-established p-type dopant on GaN epitaxial thin films [1]. The Mg-doped GaN thin films were respectively grown on an amorphous-carbon substrate of $0.4 \mathrm{~mm}$ thickness, and on a quartz glass substrate on which a heavily Ge-doped conductive $\mathrm{GaN}$ underlayer was grown. The growth temperature of the films was $900^{\circ} \mathrm{C}$, and $\mathrm{Mg}$ was doped to the films at the $\mathrm{Mg}$ cell temperature of $370^{\circ} \mathrm{C}$.

The conducting types of the obtained thin films were evaluated by the ECV measurements. KOH aquatic solution was used for fabrications of Schottky contacts to the Mg-doped GaN thin films. On the other hand, the amorphous-carbon substrate has relatively high conductivity and an ohmic relationship to the $\mathrm{Mg}$ doped $\mathrm{GaN}$ thin film. The heavily Ge-doped GaN thin film grown as the conductive underlayer on the quartz glass substrate also has a similar ohmic relationship to the Mg-doped GaN thin film. Therefore, the amorphous-carbon substrate and the heavily Ge-doped GaN underlayer were respectively used as ohmic contacts in the ECV measurements.

Figure 9 shows the Mott-Schottky plots about the Mg-doped GaN thin films obtained from the ECV measurements. The directions of the slopes in these plots are clearly different between the cases of the Mg-doped GaN thin films and the undoped n-type GaN thin film. Usually, undoped GaN shows n-type conduction because of naturally occurred nitrogen vacancies or excess metallic Ga. It can be determined that the undoped GaN thin film has n-type conduction property from the result of the ECV measurement as shown in the Figure 9(c). On the other hand, the measurement results on the Mg-doped thin films show clearly opposite direction of the slopes, that is, the slopes declined with the increase of the applied voltage. Therefore, it can be determined that the conduction type of the each Mg-doped film is p-type. The ECV measurements were carried out under applying alternating voltage of $69 \mathrm{~Hz}$ to avoid effects of the relatively high impedance of the $\mathrm{KOH}$ aquatic solution on the decrease of applied voltage to the GaN thin films. Therefore, estimated values of acceptor concentrations in the films might include the number of non-activated acceptors. Nevertheless, it was shown that p-type GaN thin films could be obtained on such non-single-crystalline substrates.

\section{Conclusion}

$\mathrm{GaN}$ and $\operatorname{In}_{\mathrm{x}} \mathrm{Ga}_{1-\mathrm{x}} \mathrm{N}$ thin films were directly grown on several non-single-crystalline substrates by the MBE

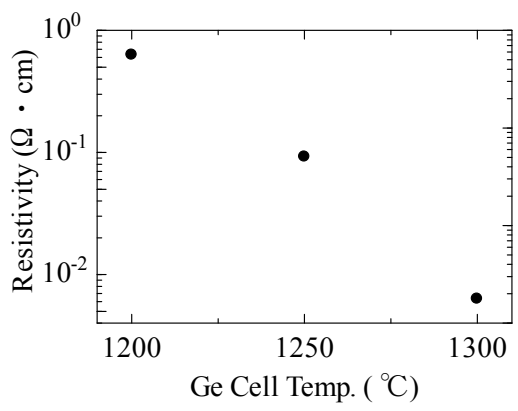

Figure 8. Variation in the resistivity of the Ge doped GaN thin films directly grown on the quartz glass substrate. The growth temperature of the film was $900^{\circ} \mathrm{C}$.


Figure 9. Results of the ECV measurements about the Mg-doped GaN thin films grown on the (a) amorphous-carbon and (b) heavily Ge-doped GaN-underlayer-grown quartz glass substrates. A result about an undoped n-type GaN thin film grown on the amorphous-carbon substrate is also shown in figure (c) as a reference. 
apparatus. Their crystallinities of each film were highly c-axis oriented, and no phase separation was observed in the $\mathrm{In}_{\mathrm{x}} \mathrm{Ga}_{1-\mathrm{x}} \mathrm{N}$ thin films. Near band-edge emissions were respectively observed in their PL spectra, and the emission intensities were largely enhanced by Ge-doping to the films. Ge-doping was also effective to control n-type conductivity of the GaN thin films even when they were grown on the non-single crystalline substrate. ECV measurements were carried out on the Mg-doped GaN thin films and p-type conductions were confirmed about each film.

\section{Acknowledgements}

A part of this work was supported by JSPS KAKENHI (Grant Number 25420314).

\section{References}

[1] Amano, H., Kito, M., Hiramatsu, K. and Akasaki, I. (1989) Japanese Journal of Applied Physics, 28, L2112-L2114.

[2] Akasaki, I., Amano, H., Kito, M. and Hiramatsu, K. (1991) Journal of Luminescence, 48-49, 666-670.

[3] Nakamura, S., Mukai, T. and Senoh, M. (1994) Applied Physics Letters, 64, 1687.

[4] Nakamura, S., Senoh, M., Nagahama, S., Iwasa, N., Yamada, T., Matsushita, T., Kiyoku, H. and Sugimoto, Y. (1996) Japanese Journal of Applied Physics, 35, L74.

[5] Davydov, V.Yu., Klochikhin, A.A., Emtsev, V.V., Kurdyukov, D.A., Ivanov, S.V., Vekshin, V.A., Bechstedt, F., Furthmuller, J., Aderhold, J., Graul, J., Mudryi, A.V., Harima, H., Hashimoto, A., Yamamoto, A. and Haller, E.E. (2002) Physica Status Solidi (b), 234, 787.

[6] Wu, J., Walukiewicz, W., Yu, K.M., Ager III, J.W., Haller, E.E., Lu, H., Schaff, W.J., Saito, Y. and Nanishi, Y. (2002) Applied Physics Letters, 80, 3967.

[7] Matsuoka, T., Okamoto, H., Nakao, M., Harima, H. and Kurimoto, E. (2002) Applied Physics Letters, 81, 1246.

[8] Maruska, H.P. and Tietjen, J.J. (1969) Applied Physics Letters, 15, 327.

[9] Tnasley, T.L. and Foley, C.P. (1984) Electronics Letters, 20, 1066-1068.

[10] Guo, Q., Shingai, N., Nishio, M. and Ogawa, H. (1998) Journal of Crystal Growth, 189/190, 466-470.

[11] Takai, O., Ikuta, K. and Inoue, Y. (1998) Thin Solid Films, 318, 148-150. http://dx.doi.org/10.1016/S0040-6090(97)01154-1

[12] Takai, O. (1984) Proceedings of the Society for Information Display, 25, 305.

[13] Sato, Y., Kurosaki, A. and Sato, S. (1998) Journal of Crystal Growth, 189-190, 42-46. http://dx.doi.org/10.1016/S0022-0248(98)00153-5

[14] Yagi, S. (1999) Japanese Journal of Applied Physics, 38, L792-L795. http://dx.doi.org/10.1143/JJAP.38.L792

[15] Kim, D.J., Park, S.E., Kim, H.J., Ryu, J.K., Byungsung, O. and Pak, S.S. (2003) Japanese Journal of Applied Physics, 42, 7349-7353. $\mathrm{http}: / / \mathrm{dx}$. doi.org/10.1143/JJAP.42.7349

[16] Keller, S., Lu, J., Mishra, U.K., DenBaars, S.P. and Speck, J.S. (2012) Physica Status Solidi A, 209, 431-433. http://dx.doi.org/10.1002/pssa.201100349

[17] Park, D.C., Ko, H.C., Fujita, S. and Fujita, S. (1998) Japanese Journal of Applied Physics, 37, L294-L296. http://dx.doi.org/10.1143/JJAP.37.L294

[18] Butcher, K.S.A., Afifuddin, P., Chen, P.T., Godlewski, M., Szczerbakow, A., Goldys, E.M., Tansley, T.L. and Freitas Jr., J.A. (2000) Glass Substrates for GaN Using ZnO Buffer Layers. Proceedings of Optoelectronic and Microelectronic Materials and Devices, COMMAD 2000, Bundoora, 6-8 December 2000, 535-538. http://dx.doi.org/10.1109/COMMAD.2000.1023005

[19] Iwata, K., Asahi, H., Asami, K., Kuroiwa, R. and Gonda, S. (1997) Japanese Journal of Applied Physics, 36, L661L664. http://dx.doi.org/10.1143/JJAP.36.L661

[20] Murata, N., Tochishita, H., Shimizu, Y., Araki, T. and Nanishi, Y. (1998) Japanese Journal of Applied Physics, 37, L1214-L1216. http://dx.doi.org/10.1143/JJAP.37.L1214

[21] Sato, Y., Hishinuma, T. and Sato, S. (2001) Japanese Journal of Applied Physics, 40, 4516-4517. http://dx.doi.org/10.1143/JJAP.40.4516

[22] Sato, Y., Hishinuma, T. and Sato, S. (2002) Physica Status Solidi (c), 0, 120-123.

[23] Yamada, K., Asahi, H., Tampo, H., Imanishi, Y., Ohnishi, K. and Asami, K. (2001) Applied Physics Letters, 78, 28492851. http://dx.doi.org/10.1063/1.1371528 
[24] Zhong, M.M., Qin, F.W., Liu, Y.M., Wang, C., Bian, J.M., Wang, E.P., Wang, H. and Zhang, D. (2014) Journal of Alloys and Compounds, 583, 39-42. http://dx.doi.org/10.1016/j.jallcom.2013.08.153

[25] Sato, Y., Hishinuma, T. and Sato, S. (2003) IEICE Transactions on Electronics, E86-C, 1002-1006.

[26] Bour, D.P., Nickel, N.M., van de Walle, C.G., Kneissl, M.S., Krusor, B.S., Mei, P. and Johnson, N.M. (2000) Applied Physics Letters, 76, 2182. http://dx.doi.org/10.1063/1.126291

[27] Choi, J.H., Zoulkarneev, A., Kim, S.I., Baik, C.W., Yang, M.H., Park, S.S., Suh, H., Kim, U.J., Son, H.B., Lee, J.S., Kim, M., Kim, J.M. and Kim, K. (2011) Nature Photonics, 5, 763-769. http://dx.doi.org/10.1038/nphoton.2011.253

[28] Koide, N., Kato, H., Sassa, M., Yamasaki, S., Manabe, K., Amano, H., Hiramatsu, K. and Akasaki, I. (1991) Journal of Crystal Growth, 115, 639-642. http://dx.doi.org/10.1016/0022-0248(91)90818-P

[29] Nakamura, S., Pearton, S. and Fasol, G. (2000) The Blue Laser Diode. 2nd Edition, Springer, 103-112. http://dx.doi.org/10.1007/978-3-662-04156-7 6

[30] Sato, Y. and Matsunaga, T. (2014) Materials Science Forum, 783-786, 1652-1657.

http://dx.doi.org/10.4028/www.scientific.net/MSF.783-786.1652 